\title{
The effectiveness of latex wound model on wound dressing skill of the nursing students
}

\author{
Benyaporn Bannaasan* \\ Faculty of Nursing, Thammasat University, Pathum Thani, Thailand
}

Received: April 26, 2020

DOI: $10.5430 /$ jnep.v10n10p68
Accepted: June 27, 2020

URL: https://doi.org/10.5430/jnep.v10n10p68

\begin{abstract}
Wound dressing is a skill which must be able to be performed by all nurses. If the practical ability of a nurse is weak, it will affect the quality of patient care. The objective of this research is to study the effectiveness of the latex wound model for wound dressing training on wound dressing skills of the nursing student. The latex wound model is a device used in practice which is made from rubber. The samples are the 60 second-year nursing students. Simple random sampling was applied in the selection of samples to be an experimental group and a control group for 30 persons per group. The latex wound model was provided to the experimental group for wound dressing skill training at the dormitory for a seven day period. A personal data questionnaire, wet dressing skill evaluation form, and dry dressing skill evaluation form were used for data collection. The data were analyzed using descriptive statistics, Wilcoxon Signed Ranks Test and Mann-Whitney U Test. The results indicated that: 1) the mean score of wet dressing skill and dry dressing skill after the intervention were significantly higher than before the intervention $(p<.05)$; 2) the mean score of wet dressing skill and dry dressing skill of the experimental group were higher than that of the control group, who was given the explanation of research procedures and the use of latex wound model, at statistical significance $(p<.05)$. The findings imply that the use of the latex wound model for wound dressing training could enhance the wound dressing practical skill of the nursing students.
\end{abstract}

Key Words: Wound model, Wound dressing, Wound dressing skill, Nursing student

\section{INTRODUCTION}

Nursing is a key to health care, ${ }^{[1]}$ and training is a key to the nurse's instruction. ${ }^{[2]}$ Good skill of the nursing student means good care provided to the sick person. Therefore, training, together with theoretical study are required for nursing students to acquire knowledge and understanding prior to field implementation. Wound dressing is contained in the basic nursing course to ensure correct wound dressing by the nursing students for the patients. ${ }^{[3-8]}$ The wound dressing training of the nursing students in a university in Thailand consists of model training, at the fundamental nursing laboratory and the field training with the patients at the training sites prior to the field practice with the patients. The students will be instructed for theory and training in wound dressing at least once per person. The students are divided into sub-groups for the full learning, both in studying hours and the self-training at Fundamental laboratory, after studying hours are arranged. However, the students can carry out skill training at least 1-2 times per person only due to the limited studying hours and failure to schedule study after studying hours, possibly affecting the practical skill and availability of few wound dressing experiences prior to the field practice with the patients.

A lack of wound dressing skills of nurses, both dry dressing and wet dressing, may cause several patient impacts, such

\footnotetext{
*Correspondence: Benyaporn Bannaasan; Email: benyaporn@ nurse.tu.ac.th; Address: Faculty of Nursing, Thammasat University, Rangsit Campus, Klong Nueng, Klong Luang, Pathum Thani, 12121, Thailand.
} 
as pain and wound infection, resulting in a longer hospitalization period, or loss of treatment income. If there is a correct way of wound dressing technique is applied, the rate of infection will be reduced, and wound healing will be promoted. ${ }^{[9]}$ Thus, the development of good practical skills for the students is essential. However, the finding from the current situation indicates lesser wound dressing training of the nursing students with patients since the University is an educational setting of various faculties relating to the science in health. Especially the practice in the same patient by the students of several faculties, sometimes nursing students are unable to do the wound dressing of that patient. The number of practice sessions for nursing students is therefore reduced. Moreover, according to the current treatment plan, doctors will open the operated wound and dress it by themselves, resulting in a further lesser opportunity for training of the nursing students with the patients even though it is essential for acquiring a good practical skill of the nursing students from the regular rehearsal ${ }^{[10]}$ and practice until becoming expert. Thus, in the learning and teaching management in training of the nursing students, the instructors have managed teaching using a model to support the training.

A latex wound model is made from rubber, which includes both a wet dressing type and a dry dressing type, for the wound dressing training has served as an instruction media to be used by the students for training at any place and anytime, which are favorable for the student learning. The students can borrow the latex wound model for self-training at the dormitory, contributing to learning encouragement, without limitation of place and time. Moreover, practicing at a dormitory is like an environment that is conducive to motivation and enthusiasm. The more frequent training of the students until being familiar and expert and having a suitable wound dressing skill, and promotion of the excellent attitude towards learning and building the confidence in nursing activity practice. ${ }^{[11]}$ Moreover, the proper practical result has also contributed to the reduction of complications, resulting in an improvement in service quality and patient satisfaction in clinics.

\section{Aim AND HYPOTHESES}

This research is a part of Research \& Development (R \& D) which has 2 main parts, which are 1) the development of the latex Wound Model and 2) evaluation of the effectiveness of the latex Wound Model. The aim of this research is to study the effectiveness of the latex wound model for wound dressing training on wound dressing skills of the nursing student. The following are the research hypotheses. 1) The group of nursing students receiving the training with the latex wound model has higher wound dressing skills after than before training with the latex wound model. 2) The group of nursing students receiving the training with the latex wound model has higher wound dressing skills than the group who did not receive the training with the latex wound model.

\section{MEDTHOD}

\subsection{Study design}

This research is quasi-experimental research for two groups, and the pre-experimental and post-experimental measurements are performed (see Figure 1).

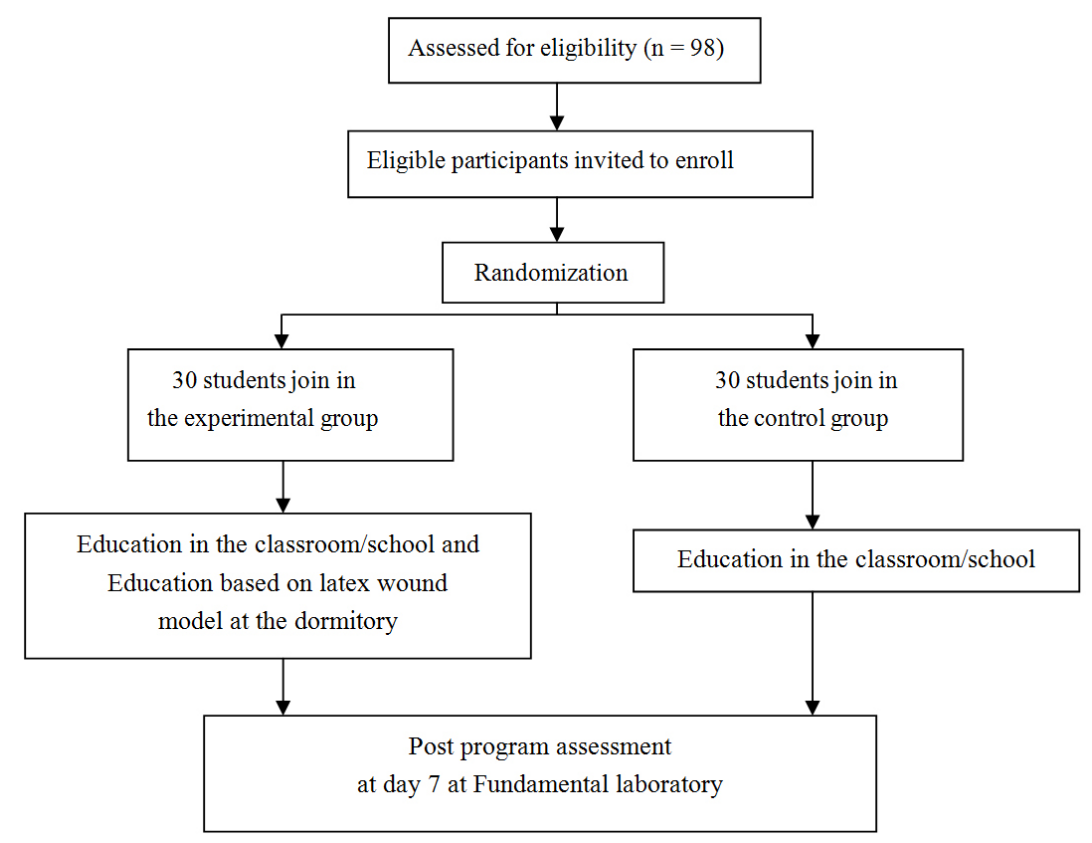

Figure 1. Flow diagram of participants 


\subsection{Samples and setting}

The participants are the second-year nursing students of a university in the central region, Thailand. The characteristics of the participants are as follows: 1) being a second year nursing student who has already been taught wound dressing theory, 2) being a person who is inexperienced in wound dressing with the real service users, 3) willing to participate in the program. The participants will be instructed for theory and training in wound dressing at least once per person for teaching at school. The participants who are the experimental group will receive the latex wound model for wound dressing skills at the dormitory for seven days. The control group was only explained about how to use the latex wound model and did not receive the model for training at the dormitory. In this research, the researcher calculated the sample size in accordance with the quasi-experimental research design, conducted power analysis with $\mathrm{G}$ power program version 3.1.9.2, defined the value of alpha $=.05$ power $=.08$, and medium effect size $=.7,^{[12]}$ conducted a one-tailed test, and acquired the sample size in a total of 60 persons for 30 persons per group.

\subsection{Ethical considerations}

The researcher has protected the right of the participants by proposing the research outline to the third Human Research Ethics Sub-Committee, Thammasat University, for approving on researching and passing the consideration of the Human Research Ethics Sub-Committee according to the research outline supporting document No. 086/2560. After receiving permission, the researcher has met the participants for the self-introduction and clarification to the participants to be informed of the research objective, research procedure, research benefit, and data collection, and then asked for collaboration to participate in the research. The participants were entitled to freely make decisions on research participation. In the case where the participants agreed to participate in the study, the researcher would ask the examples to affix their signatures to give consent on the research participation before each research commencement. The researcher will collect the personal data of the participants as confidential and use an encryption instead of the real name. Only the research conclusion result will be particularly disclosed. In the case where the students denied to participate in the research, or agreed to participate in the research and then denied later before the research completion, the students were allowed to do so without clarification of his/her reason to the researcher. Those denial results would have no impact on the students with respect to the learning and teaching evaluation of the students.

\subsection{Research instruments}

\subsubsection{Data collection instrument}

Personal Questionnaire: a questionnaire constructed by the researcher from the literature review, and consisting of queries in the nature of filling statements and selecting multiple-choice regarding sex, age, and experience in wound dressing while studying or in the laboratory.

Wet Dressing Skill Evaluation Form: a questionnaire constructed by the researcher from the literature review, and consisting of 10 items in total. The rating scale query consists of 1-5 score level. The questions are classified into four individual aspects which are 1) pre-practical readiness for 3 items, 2) aseptic for 2 items, 3) wound dressing process for 4 items, and 4) nursing record for 1 item. The queries are positive queries containing five multiple choices. The rating criteria is $5=$ Complete and active practice and $1=$ Noncompliance with the determined procedure. The samples of the queries include "Evaluation on nature of the wound and wound drainage" and "Recording of nature of the wound, wound drainage, and detected abnormality." The scores are from 10-50 scores. According to the score interpretation, high mean means that the said person has high wet dressing skills and low mean means that the person has low wet dressing skills.

Dry Dressing Skill Evaluation Form: a questionnaire constructed by the researcher from the literature review, and consisting of 10 items in total. The rating scale query consists of 1-5 score level. The questions are classified into four individual aspects which are 1) pre-practical readiness for 3 items, 2) aseptic for 2 items, 3) wound dressing process for 4 items, and 4) nursing record for 1 item. The queries are positive queries containing five multiple choices. The rating criteria is $5=$ Complete and active practice and $1=$ Noncompliance with the determined procedure. The samples of the queries include "Evaluation on nature of the wound and wound drainage" and "Recording of nature of the wound, wound drainage, and detected abnormality". The scores are from 10-50 scores. According to the score interpretation, high mean means that the said person has high dry dressing skills and low mean means that the person has low dry dressing skills.

\subsubsection{Experimental instruments}

Latex Wound Model: There are two types of wound model consisting wet wound and dry wound.

Wound Dressing Handbook consists of 10 wet dressing procedures and 10 dry dressing procedures developed by the researcher.

The intervention program includes an application of latex 
wound model and Wound Dressing Handbook for wound dressing skill training at the dormitory for a seven day period.

\subsubsection{Content validity test}

Three experts, comprising of one doctor who is expert in the invention, one nursing instructor who is expert in the invention, and one nurse with working experience of no less than 5 years, conducted content validity test on Wet Dressing Skill Evaluation Form and Dry Dressing Skill Evaluation Form. Content validity was acquired at 1.00 and 1.00 , respectively.

\subsubsection{Reliability Test}

The researcher tried out the instrument which was conducted for content validity test and improved by the experts, the reliability of the instruments were tested with a group of 10 second year nursing students who had the same characteristics as the study population, and analyzed to determine the reliability of the questionnaire using Cronbach's Alpha Coefficient Method. A reliability of 0.727 was acquired from the Wet Dressing Skill Evaluation Form, and after using it with 60 participants, reliability of 0.717 was acquired. A reliability of 0.761 was acquired from the Dry Dressing Skill Evaluation Form, and after using it with 60 participants, a reliability of 0.722 was acquired.

\subsection{Data collection}

Two research assistants of the researcher in conducting the research in the stage of using an invented model consist of one nurse instructor who evaluates the practical skill of the students, and one officer for preparing the place where is Fun- damental laboratory, model, and practical equipment. The researcher will ask the participants to reply to the personal data questionnaire. The nurse instructor, who is a research assistant, will observe the practice and evaluate wet dressing skills and dry dressing skills, and instruct the participants to use the invented latex wound model. The research assistants will not know whether the participants are the experimental group or the control group. This procedure will be taken around 15-20 minutes.

\subsection{Data analysis}

Personal data are analyzed by descriptive statistics for determining the percentage, mean and standard deviation. Fisher's exact test and Chi-square test are used to test the difference of the personal data. Wilcoxon Signed Ranks test is used to test the difference between the pre-experimental and postexperimental wound dressing skills, and Mann-Whitney $\mathrm{U}$ Test is used to test the difference of wound dressing skill between the experimental group and the control group.

\section{Results}

As shown in Table 1, most samples were female (93.30\%), with age 19-21 years whereas most of them were aged 20 years old $(50 \%)$, having experience in wet dressing while studying/in the laboratory for 2-6 times whereas most of them had the experiences for 3 times or $43.30 \%$, and having experience in dry dressing while studying/in the laboratory for 1-6 times whereas most of them had experienced for 3 times or $36.70 \%$.

Table 1. Demographic characteristics of the participants

\begin{tabular}{|c|c|c|c|c|c|}
\hline Demographic characteristic & $\begin{array}{l}\text { Total } \\
\text { n (\%) }\end{array}$ & $\begin{array}{l}\text { Control group } \\
\text { n (\%) }\end{array}$ & $\begin{array}{l}\text { Experimental group } \\
\text { n (\%) }\end{array}$ & $\begin{array}{l}\text { Statistic } \\
\text { test value }\end{array}$ & $p$-value* \\
\hline Gender & & & & $1.071^{*}$ & .612 \\
\hline Female & $56(93.30)$ & $27(90.00)$ & $29(96.70)$ & & \\
\hline Male & $4(6.70)$ & $3(10.00)$ & $1(3.30)$ & & \\
\hline Age (year) & & & & $6.749^{\dagger}$ & .017 \\
\hline 19 & $26(43.30)$ & $15(50.00)$ & $11(36.70)$ & & \\
\hline 20 & $30(50.00)$ & $11(36.70)$ & 19 (63.30) & & \\
\hline 21 & $4(6.70)$ & $4(13.30)$ & $0(0.00)$ & & \\
\hline \multicolumn{4}{|c|}{ Experiences in wet dressing while studying/in the laboratory (times) } & $3.258^{\dagger}$ & .516 \\
\hline 2 & $1(1.70)$ & $0(0.00)$ & $1(3.30)$ & & \\
\hline 3 & $26(43.30)$ & $16(53.00)$ & $10(33.30)$ & & \\
\hline 4 & $21(35.00)$ & $9(30.00)$ & $12(40.00)$ & & \\
\hline 5 & $9(15.00)$ & $4(13.00)$ & $5(16.70)$ & & \\
\hline 6 & $3(5.00)$ & $1(3.00)$ & $2(6.70)$ & & \\
\hline \multicolumn{4}{|c|}{ Experiences in dry dressing while studying/in the laboratory (times) } & $4.735^{\dagger}$ & .449 \\
\hline 1 & $7(11.70)$ & $4(13.30)$ & $3(10.00)$ & & \\
\hline 2 & $13(21.70)$ & $6(20.00)$ & $7(23.30)$ & & \\
\hline 3 & $22(36.70)$ & $10(33.30)$ & $12(40.00)$ & & \\
\hline 4 & $12(20.00)$ & $5(16.70)$ & $7(23.30)$ & & \\
\hline 5 & $4(6.70)$ & $4(13.30)$ & $0(0.00)$ & & \\
\hline 6 & $2(3.30)$ & $1(3.30)$ & $1(3.30)$ & & \\
\hline
\end{tabular}


The comparative result of the personal data between the experimental group and the control group indicated that both groups of participants were indifferent at statistical significance $(p>.05)$ regarding sex, experiences in wet dressing while studying/in the laboratory, and experiences in dry dressing while studying/in the laboratory, except age that both groups of participants were different at statistical significance $(p<.05)$.

As shown in Table 2, The comparative result of the mean score of wet dressing skill between before latex wound model training and after latex wound model training in the experimental group and the control group showed that the mean score of post-experimental wet dressing skill was higher than that of pre-experimental wet dressing skill at statistical significance $(p<.05)$.

The comparative result of the mean score of wet dressing skill before latex wound model training between the experimental group and the control group indicated that the mean score of wet dressing skill was indifferent at statistical significance $(p<0.5)$. The comparative result of the mean score of wet dressing skill after latex wound model training between the experimental group and the control group described that the mean score of wet dressing skill of the experimental group was higher than that of the control group at statistical significance $(p<.05)$.

Table 2. Wet dressing skill score before training and after training of the experimental group and the control group

\begin{tabular}{|c|c|c|c|c|c|}
\hline \multirow{2}{*}{$\begin{array}{l}\text { Wound Dressing Skill } \\
\text { (Wet Wound) }\end{array}$} & \multicolumn{2}{|l|}{ Mean \pm SD } & \multirow{2}{*}{$\begin{array}{l}\text { Mean rank } \\
\text { (Sum of rank) }\end{array}$} & \multirow{2}{*}{$\mathbf{Z}$} & \multirow{2}{*}{$p$-value } \\
\hline & Before training & After training & & & \\
\hline Experimental Group & $23.63 \pm 2.90$ & $37.46 \pm 5.26$ & $15.97(463.00)$ & -4.748 & $.000^{*}$ \\
\hline Control Group & $22.60 \pm 3.53$ & $27.93 \pm 4.11$ & $16.33(392.00)$ & -3.779 & $.000^{*}$ \\
\hline $\mathrm{Z}$ & -1.445 & -5.282 & & & \\
\hline$p$-value $\mathrm{e}^{\S}$ & .074 & $.000^{*}$ & & & \\
\hline
\end{tabular}

As shown in Table 3, the comparative result of the mean score of dry dressing skill between before latex wound model training and after latex wound model training in the experimental group and control group indicated that the mean score of post-experimental dry dressing skill was higher than that of pre-experimental dry dressing skill at statistical significance $(p<.05)$.

The comparative result of the mean score of dry dressing skill before latex wound model training between the experimental group and the control group indicated that the mean score of dry dressing skill was indifferent at statistical significance $(p<0.5)$. The comparative result of the mean score of dry dressing skill after latex wound model training between the experimental group and the control group described that the mean score of dry dressing skill of the experimental group was higher than that of the control group at statistical significance $(p<.05)$.

Table 3. Dry dressing skill score before training and after training of the experimental group and the control group

\begin{tabular}{|c|c|c|c|c|c|}
\hline \multirow{2}{*}{$\begin{array}{l}\text { Wound Dressing Skill } \\
\text { (Dry Wound) }\end{array}$} & \multicolumn{2}{|l|}{ Mean \pm SD } & \multirow{2}{*}{$\begin{array}{l}\text { Mean rank } \\
\text { (Sum of rank) }\end{array}$} & \multirow{2}{*}{$\mathbf{Z}$} & \multirow{2}{*}{$p$-value } \\
\hline & Before training & After training & & & \\
\hline Experimental Group & $24.10 \pm 3.83$ & $37.36 \pm 5.32$ & $15.50(434.00)$ & -4.695 & $.000^{*}$ \\
\hline Control Group & $22.60 \pm 3.46$ & $28.16 \pm 4.11$ & $14.96(374.00)$ & -3.899 & $.000^{*}$ \\
\hline Z & -1.472 & -5.277 & & & \\
\hline P-value§ & .070 & $.000^{*}$ & & & \\
\hline
\end{tabular}

\section{Discussion}

The results indicated that the mean score of wound dressing skill of the nursing students after latex wound model training was higher than that before latex wound model training at statistical significance $(p<.05)$, and the mean score of wound dressing skill of the nursing students after latex wound model training was higher than before latex wound model training at statistical significance $(p<.05)$. It was in accordance with the hypothesis which was consistent with the study indicated that the nursing students who used active learning were positively evaluated by the clinical preceptors in the ward. The report described that the nursing students were enthu- 
siastic about the learning process, particularly in a request for demonstrating the nursing skill. ${ }^{[13]}$ It was similar to the studies which the finding indicated that a pregnancy examination model, a portable adult arm model, an artificial arm and blood vessel model, a human arm model, self-video learning, video media helped nursing students increase the pregnancy examination skill, ${ }^{[14]}$ venipuncture skills, peripheral intravenous cannulation skills, ${ }^{[15,16]}$ academic achievement and blood collection skills, ${ }^{[17]}$ the cleaning technique skill, ${ }^{[18]}$ and nursing practical skill. ${ }^{[19]}$ The students who studied by using the model gained higher nursing skills than those who studied in the normal manner. However, it might be due to a model that is a type of three-dimensional media which is commonly used for students to be able to easily understand and teachers can teach exactly the purpose of teaching and learning. ${ }^{[20]}$ Also, the use of the latex wound model as a tool to support the self-learning of students through the thinking process in order to know their own learning needs. Set their own learning goals. Allocate the use of the existing latex wound model for their own benefit. ${ }^{[21]}$ Allocate time to practice wounds in the dormitory yourself by allowing students to practice during their free time from study without scheduling the studying time from the instructors, and without the time or place limitation in training. The training was performed upon the readiness of the students with an additional training period of 7 days, resulting in the student improvement on their practical skills. Moreover, the latex wound model training was similar to simulation, resulting in the confidence of the students in practice ${ }^{[11,16,22-26]}$ and the ability of the students to perform several nursing practices

\section{REFERENCES}

[1] Punjot P. Nurse's role: beyond the bedside. International Journal of Nursing Education and Research. 2010 [cited 2017 May 1]; 7(3): 432-434. https://doi.org/10.5958/2454-2660.2019.00099.1

[2] Farzi S, Shahriari M, Farzi S. Exploring the challenges of clinical education in nursing and strategies to improve it: A qualitative study. Journal of Education and Health Promotion. 2018 [cited 2019 Oct 8]; 7: 115 .

[3] Senadisai S, Arpanuntikul M. Nursing intervention. Bangkok: Judthong; 2009. 573 p.

[4] Chatchaisucha S, Ucharattana P, Boonchun N. Basic skills in nursing. Bangkok: N P Press; 2007. 344 p.

[5] Senadisai S, Prapipanich W. Basic nursing care: concept and practice. Bangkok: Judthong; 2011. 761 p.

[6] Pumduang A. Fundamentals of nursing: nursing practice. Bangkok: Chulalongkorn University; 2016. 383 p.

[7] Potter PA, Perry AG, Stockert PA, et al. Fundamentals Nursing. Missouri: Mosby; 2013. 1358 p.

Published by Sciedu Press in the virtual situation until they were confident before nursing the patients. The environment is one of the factors that help students to learn and develop students quality ${ }^{[27]}$ and influence learning in terms of motivation and enthusiasm. ${ }^{[28]}$ As well as practicing wound dressing at a dormitory that supports the needs of students about the environment while studying. Nursing students want to have comfort breaks and fun through and between lessons. They want to play games to refresh their minds, body, and souls even doing exercises before class. The restrooms also need to be easily accessible for the students to prevent students from missing a lot of work while using the restrooms or going out to drink water. ${ }^{[29]}$ These needs, students can make and access when they are in the dormitory so they can achieve a learning outcome. That is having good skills.

\section{Conclusion}

The finding of this research results indicated that the use of the latex wound model for wound dressing training could enhance the wound dressing practical skill of the nursing students. Therefore, nursing instructors should encourage students to use the latex wound model to practice wound dressing skills at the dormitory after teaching in the laboratory to increase skills before practicing with patients.

\section{Limitation}

The number of participants in this study was small, so the generalization of the results from this study is limited.

\section{CONFlicts of InTEREST Disclosure}

The authors declare that there is no conflict of interest.
[8] Craven R, Hirnle C, Jensen S. Fundamentals of nursing: human health and function. Philadelphia: Lippincott Williams \& Wilkins; 2013. 1487 p.

[9] Suwannasarn K. Nursing care in patient with wound and Inflammation [internet]. n.d. [cited $2020 \mathrm{Apr} 1$ ]. Available from: http://courseware.npru.ac.th/course2. php?course $=24$

[10] Solvik E, Struksnes S. Training nursing skills: a quantitative study of nursing students' experiences before and after clinical practice. Nursing Research and Practice [internet]. 2018 [cited 2019 Oct 15]. PMid:29713528 https://doi.org/10.1155/2018/8984028

[11] Chiannilkulchai N. Development of an artificial pus wound model to improve second-year nursing students' skill in performing wound swab culture. Thai Journal of Nursing Council [internet], 2016 [cited 2020 Jun 19]; 31(1): 32-43.

[12] Shin S, Park JH, Kim JH. Effectiveness of patient simulation in nursing education: Meta-analysis. Nurse Education Today. 2015; 35(1): 176-182. PMid:25459172 https://doi.org/10.1016/j.nedt.2014.09.009

[13] Leong CSU, Clutter LB. Active learning improves nursing student clinical performance in an academic institution in Macao. 
Chinese nursing research [internet], 2015 [cited 2020 Apr 1]; 2: 35-39. https://doi.org/10.1016/j.cnre.2015.08.001 Available from: https://www.sciencedirect.com/science/article/pii/s2095771815300025

[14] Kaoaiem H, Duandee K. The evaluation of pregnancy model and vcd of obstetrical examination in pregnant women among nursing student of Royal Thai Army Nursing College. Journal of The Royal Thai Army Nurses. 2013 [cited 2020 Apr 1]; 4(3): 189-195.

[15] Bannaasan B. Portable adult arm model for nursing students' venipuncture and peripheral intravenous cannulation practice. Thai Journal of Nursing Council [internet], 2017 [cited 2020 Apr 1]; 32(3): 38-49.

[16] Ruamwong N, Hemchayat M, Loysak B. The effects of using arm model and imitated blood vessel on the ability to perform venous puncture procedure in nursing students of Phrapokklao Nursing College Chanthaburi [internet]. 2011 [cited 2020 Apr 1]. Available from: http://web.pnc.ac.th/html/vijai.php

[17] Ratanawiboolsook N. The results of using a model for blood drawing for first year students in the clinical pathology department, Kanchanabhisek Institute of Medical and Public Health Technology [master's thesis]. [Bangkok]: Ramkhamhaeng University; 2012. 138 p.

[18] Suwan N, Kasatpibal N, Sawasdisingha P. Effects of student-centered teaching on knowledge, practice, and satisfaction of sterile techniques among second year nursing students [internet]. c2009 [cited 2020 Apr 1]. Available from: https://tdc.thailis.or.th/tdc/se arch_result.php

[19] Klaypeth P, Plengkratoke S, Konyai J, et al. Satisfaction and learning outcomes of nursing students about learning media for promote to basic nursing skills [internet]. c2013 [cited 2020 Apr 1]. Available from: https://tdc.thailis.or.th/tdc/search_result.php

[20] Suprasert A. KU-NR Models: Natural rubber models for education. c2018 [cited 2020 Apr 1]. Available from: http://www3.rdi.ku. ac.th/exhibition/Techno_/index59.html

[21] Knowles MS. Self-directed learning: a guide for learners and teachers. Englewood Cliffs: Cambridge Adult Education; 1975. 135 p.
[22] Cordeau MA. Teaching holistic nursing using clinical simulation: a pedagogical essay. Journal of Nursing Education and Practice. 2013 [cited 2020 Apr 1]; 3(4): 40-50. https://doi.org/10.5430/jnep.v3n4p40

[23] Valizadeh L, Amini A, Fathi-Azar E, et al. The effect of simulation teaching on baccalaureate nursing students' self-confidence related to peripheral venous catheterization in children: a randomized trial. Journal of Caring Sciences [internet]. 2013 [cited 2020 Apr 1]; 2(2): 157-164.

[24] Ouamkum N. Development of a low-cost phantom for ultrasound guided needle insertion training [master's Thesis]. [Bangkok]: King Mongkut's University of Technology North Bangkok; 2014. 146 p.

[25] Guerra DS. Undergraduate nursing students' experiences with learning about wound care [Dissertation]. [Alabama]: University of Alabama; 2017. $147 \mathrm{p}$.

[26] Redmond C, Hardie P, Davies C, et al. Increasing competence in wound care: A cross-sectional study to evaluate use of a virtual patient by undergraduate student nurses. Nurse Education in Practice. 2020 [cited 2020 Jun 19]; 44. PMid:32244047 https://doi.org/10.1016/j.nepr.2020.102774

[27] Phrakhrubaidika Monthon Khamago. Environmental influence of contributing learning for development of tertiary students. Journal of Yanasangvorn Research Institute [internet]. 2019 [cited 2020 Jun 19]; 10(1): 192-200.

[28] Yildiz CD, Tatik RS. Impact of flexible and non-flexible classroom environments on learning of undergraduate students. European Journal of Educational Research. 2019 [cited 2020 Jun 19]; 8(4): 1159-1173.

[29] Froneman K, Plessis E, Koen MP. Effective educator-student relationships in nursing education to strengthen nursing students' resilience [internet]. 2016 [cited 2020 Jun 19]. Available from: http://pdfs. Semanticscholar.org/f318/fa093e461981 3c409a9a0586973ac9fbc17f .pdf?_ga=2.202896087.75708 8365.1592600036-1100717951.1536910405 